\title{
Análise clínica, radiológica, macroscópica e histológica do úmero de codornas domésticas (Coturnix japonica), submetido ao implante da poliuretana derivada do polímero de mamona (Ricinnus communis) ${ }^{1}$
}

\author{
Clinical, radiological, macroscopical and histological analysis of domestic quail \\ (Coturnix japonica) humerus submitted to implant of polyurethane \\ from castor oil polymer (Ricinnus communis)
}

\author{
Juliano Bolson ${ }^{2}$ João Eduardo Schossler ${ }^{3}$ Roberta Caroline Ornes ${ }^{4}$ \\ Vanessa Mottin ${ }^{4}$ Thiago Alberti ${ }^{4}$
}

\section{RESUMO}

Na cirurgia ortopédica, são freqüentes as situações em que o cirurgião se depara com grandes perdas ósseas, provocadas especialmente por traumatismos de alta energia, tumores ou infecções. A reparação dessas fraturas requer grande conhecimento a respeito de materiais que possam ser utilizados para preencher essas falhas. Esses materiais podem ser derivados biológicos, sintéticos ou metálicos. Dentre eles, destacam-se os enxertos ósseos e os implantes de biomateriais. Com o aumento dos animais exóticos, utilizados como animais de estimação, a casuística clínica e cirúrgica dessa especialidade vem crescendo, tanto em clínicas quanto em hospitais veterinários. Particularmente, as aves constituem a maioria desses animais, $e$ entre seus problemas cirúrgicos as fraturas são os de maior destaque. O objetivo deste trabalho foi estudar o efeito clínico, radiológico, macroscópico e histológico da poliuretana derivada do polímero de mamona (Ricinnus communis) implantada no úmero de codornas domésticas (Coturnix japonica). Para isso, foram utilizadas 20 codornas, machos e fêmeas, separadas aleatoriamente em quatro grupos de cinco animais, os quais receberam o implante no úmero esquerdo, com exame clínico diário durante o período pós-operatório, avaliações radiológica imediata e quinzenal e macroscópica e histológica aos 15, 30, 60 e 90 dias. Clinicamente não foram observadas alterações locais, regionais nem sistêmicas. Ao exame radiológico, notouse aumento de densidade local, sem sinais de alteração óssea, dos tecidos circunjacentes, e de sacos aéreos. A análise macroscópica revelou que a poliuretana de mamona não foi absorvida em nenhum dos quatro grupos permanecendo implantada no seio do osso pneumático, porém, notou-se alteração em sua resistência. O exame histopatológico mostra inicialmente mínima reação inflamatória, discreta fibrose ao redor do implante e osteointegração pela presença de trabéculas e medula óssea no interior do implante. Concluiu-se que a poliuretana derivada do polímero de mamona é biocompatível em aves, podendo ser utilizada na cirurgia ortopédica, ocorrendo osteointegração.

Palavras-chave: cirurgia, ortopedia, biomaterial, mamona, aves, osteointegração.

\begin{abstract}
In orthopedic surgery there are frequently situations in which the surgeon faces severe bone losses caused by highenergy trauma, tumors or infections. Repairing these losses require knowledge about filling materials. Those materials can be biological, synthetic or metallic, with emphasis in bony grafts and biomaterial implants. The increase of the use of birds as pets is leading to an increasing number of clinical and surgical cases related to this taxon, where fractures are the most commonly observed surgical problems. The objective of this study was to evaluate clinical, radiological, macroscopic and microscopic effects of the polyurethane derived from castor oil (Ricinus communis) polymer, when implanted in the humerus of domestic quails (Coturnix japonica). Twenty male and female quails, were used randomly distributed in four groups of five individuals. The birds received the implants in the left humerus, being submitted to daily physical examination during the postoperative period, immediate and biweekly radiological examination, and macroscopic and microscopic evaluation at the $15^{\text {th }}, 30^{\text {th }}, 60^{\text {th }}$
\end{abstract}

${ }^{1}$ Parte da dissertação de mestrado do primeiro autor, submetida ao programa de Pós-graduação em Medicina Veterinária (PPGMV), Universidade Federal de Santa maria (UFSM).

${ }^{2}$ PPGMV, UFSM, Santa Maria, 97105-900, RS, Brasil. Email: jbolsonvet@yahoo.com.br. Autor para correspondência.

${ }^{3}$ Departamento de Pequenos Animais e do PPGMV, UFSM, Santa Maria, RS, Brasil.

${ }^{4}$ Curso de Graduação em Medicina Veterinária da UFSM, Santa Maria, RS, Brasil. 
and $90^{\text {th }}$ days. Clinically, there were not observed local, regional or systemic changes. Radiologically, increase in local density was observed with no signs of changes in bone or adjacent tissue, as well as in the air sacs. Macroscopic analysis revealed that the polyurethane derived from castor oil polymer was not absorbed in none of the four groups, remaining implanted within the pneumatic bone. Its resistance, however, has changed. Microscopic examination evidenced minimum inflammatory reaction, slight fibrosis around the implants, and osteointegration with presence of trabeculi and bone marrow inside the implants. Concluding, implants of polyurethane derived from castor oil polymer are biocompatible in quails, with occurrence of osteo-integration, and can be used in orthopedic surgery in this species.

Key words: surgery, orthopedic, biomaterial, castor oil, birds, osteointegration.

\section{INTRODUÇÃO}

Com o advento dos animais exóticos, utilizados como bichos de estimação, o Médico Veterinário, cada vez mais se depara com os mesmos na clínica médica e cirúrgica. Desses, os mais freqüentes são as aves e uma grande proporção dos problemas tem resolução cirúrgica. Entre os problemas cirúrgicos das aves, as fraturas são os de maior destaque (WESTFALL \& EGGER, 1979). MACCARTNEY (1994) avaliou problemas cirúrgicos em 327 pombos e concluiu que as fraturas estão presentes em $70,3 \%$ dos casos.

O sucesso da cirurgia ortopédica em aves está diretamente relacionado com as técnicas utilizadas para anular as forças mecânicas de uma fratura. Para isso, é necessária uma imobilização eficiente, permitindo assim cicatrização rápida e retorno funcional do membro afetado (BUSH, 1977). Segundo WILLIAMS et al. (1987) e MACCOY (1991), as manobras de reparo das fraturas em aves são idênticas àquelas realizadas em mamíferos. Primeiramente deve-se promover alinhamento dos fragmentos ósseos, manter a biomecânica normal e estabilização rígida, para promover rápida formação do calo ósseo, com conseqüente neoformação óssea. A completa cicatrização de uma fratura em uma ave depende ainda, do suprimento sangüíneo e da presença ou não de infecção (WITHROW, 1982) e ocorre mais rapidamente que em mamíferos devido ao alto metabolismo (NEWTON \& ZEITLIN, 1977; WISSMAN, 1999).

Estudos ortopédicos com aves vêm sendo realizados no intuito de encontrar uma maneira eficiente de proporcionar cicatrização óssea. Resultados satisfatórios, mas muitas vezes contraditórios foram encontrados, demonstrando a necessidade de mais pesquisas na área (ALIEVI, 2000).
Os conhecimentos sobre bio-polímeros evoluíram muito nas últimas décadas, principalmente com o advento da primeira classe de poliuretanos, quando foi comprovada a superioridade das uretanas vegetais sobre as resinas derivadas de minerais (BAYER, 2003).

O polímero de mamona, que é obtido a partir de dois componentes básicos: poliol e prépolímero (ambos obtidos por modificação do óleo da mamona, usando técnicas especiais de ativação uretana), é um bioativo, com módulo e elasticidade similar ao osso humano. É sintetizado a partir do óleo da mamona que é extraído de uma oleaginosa, da classe dicotilédone, ordem gerianáceas, família da euforbláceas. Foi quimicamente desenvolvido para prover sítios ativos [Grupos de hidroxila $(-\mathrm{OH})$ reagindo com os grupos isocianato (-NCO)] e o carbonato de cálcio, como material de preenchimento não ativo. Com reação de policondensação, obtevese o polímero bioethano, com uma proporção controlada e balanceada, de um (-OH) para um (-NCO) nos seus sítios ativos (CHIERICE, 2003).

De acordo com CHIERICE (2003), o implante de mamona é um produto natural, não sujeito a rejeição, com novos tecidos se formando a partir da base formada pelo mesmo, que serve como uma espécie de ponte entre os fragmentos ósseos já existentes. CAVALCA (2003) utilizou em humanos a poliuretana de mamona, em casos iniciais de artrose-desgaste da articulação, como em casos de doenças que levam à degeneração articular e teve resultados satisfatórios de recuperação mecânica dos pacientes. HIRAKI (2003), utilizando células da medula óssea de ratos, testou e confirmou a biocompatibilidade in vitro do polímero de mamona. PIRES (2001) avaliou a osteocondutividade e a osteointegração de implantes, com três formulações de poliuretana derivada da mamona, em fêmur de coelhos. Testando o polímero de mamona puro, misturado ao carbonato de cálcio ou ao fosfato de cálcio, observou que a biomassa acrescida de fosfato de cálcio tem a melhor osteocondutividade e osteointegração. Em um outro estudo, em que se implantou a poliuretana em cães na idade de crescimento, MARIA et al. (2003) concluíram que o material é biocompatível, comportando-se como espaçador ósseo, porém, sem osteointegração. MARIA et al. (2004), em um outro experimento que objetivava tratar luxação de patela, implantaram a poliuretana em sulco confeccionado na face medial proximal da tíbia de cães imaturos e concluíram que, além de ser biocompatível, o material ajuda a promover deslocamento lateral da crista tibial. 
Avaliações por imagem foram documentadas por SILVA (1997), quando estudou o comportamento do tecido ósseo, frente ao implante da biomassa de mamona em rádio de coelhos, pela análise quantitativa das radiopacidades em imagens radiográficas convencionais, o autor concluiu que este método é eficiente na avaliação do comportamento biológico do biomaterial. Em outro estudo, comparando a densidade radiográfica digital com a convencional do tecido ósseo, face ao implante do polímero de mamona em coelhos, TAVANO (1999) concluiu que a densidade digital tem a mesma qualidade diagnóstica da radiografia convencional.

Esse trabalho propõe avaliações: clínica, radiológica, macroscópica e histológica do úmero de codornas domésticas, submetido ao implante da poliuretana derivada do óleo da mamona, buscando comprovar sua biocompatibilidade e osteointegração na espécie estudada.

\section{MATERIAL E MÉTODOS}

Os animais utilizados nesta pesquisa foram tratados segundo as normas exigidas pelo COBEA (Colégio Brasileiro de Experimentação Animal). Foram utilizadas 20 codornas domésticas (Coturnix japonica), adultas, machos e fêmeas. Esses animais passaram por exame clínico geral e foram mantidos em gaiolas individuais, situadas em um galpão semifechado, por um período de adaptação e por todo o experimento, recebendo água e ração ad libidum. Separados em quatro grupos de cinco animais escolhidos ao acaso, as aves foram submetidas ao implante por meio de procedimento cirúrgico. No préoperatório, cada ave passou por um período de jejum sólido de três horas e hídrico de duas horas. Foram induzidas à anestesia geral dissociativa, com uma associação de cloridrato de cetamina ${ }^{a}$, cloridrato de xilazina $^{\mathrm{b}}$, sulfato de atropina ${ }^{\mathrm{c}}$ e citratro de fentanila ${ }^{\mathrm{d}}$, na mesma seringa, sem pré-medicação. A dose foi calculada por extrapolação alométrica interespecífica, usando como modelo um cão de 10kg. Após a indução, procedeu-se intubação oro-traqueal e o animal recebeu oxigênio a 100\%, em sistema semifechado. A anestesia foi mantida com halotano, em um vaporizador universal, vaporizado sempre que o plano anestésico superficializasse. Uma vez anestesiados, foram submetidos à depenação da região umeral esquerda e posicionados na mesa cirúrgica em decúbito lateral direito, sobre uma bolsa térmica contendo água aquecida à $\pm 41^{\circ} \mathrm{C}$.

A anti-sepsia foi efetuada, com gluconato de clorexidina ${ }^{\mathrm{f}}$ a $4 \%$, em seguida campos cirúrgicos foram aplicados, isolando a área a ser operada. O acesso ao úmero obtido por incisão de pele, divulsão entre os músculos propatagial e deltóide menor, seguido da incisão capsular foi realizado de maneira que expusesse a articulação escápula-coraco-umeral, mostrando o tubérculo maior do úmero. Um primeiro pino metálico liso (1mm) foi inserido no seio do osso pneumático de forma normógrada através do tubérculo umeral e após foi removido. Um segundo pino metálico liso (1,5mm), foi também inserido de forma normógrada, a fim de alargar o primeiro leito causado pela introdução do primeiro pino, depois também foi retirado. Os dois pinos avançavam até que atingissem o comprimento total do osso.

O defeito criado no úmero foi preenchido com blocos pré-moldados da poliuretana derivada do polímero de mamona ${ }^{g}$ (Ricinnus communis), acrescida de carbonato de cálcio. Os blocos foram moldados de modo que tomassem a forma de pinos intramedulares, baseando-se para isso na espessura de um pino metálico de diâmetro 1,5mm. Para a confecção destes moldes, a biomassa foi preparada conforme as proporções recomendadas pelo fabricante, utilizando 20 gramas de carbonato de cálcio, 16 mililitros de poliol e 20 mililitros de prépolímero. Os pinos moldados foram esterilizados em autoclave. Após a inserção normógrada do pino prémoldado, efetuou-se irrigação do sítio cirúrgico com solução fisiológica e foi procedida capsulorrafia, miorrafia e dermorrafia com a utilização de fio absorvível poliglactina $910^{\mathrm{h}}$, número 5-0, num padrão simples separado. A ave foi envolvida em papel jornal de forma que ficasse imobilizada até a completa recuperação anestésica.

Durante o trans-operatório foi instituída profilaxia antibiótica utilizando enrofloxacinai, além de um antiinflamatório (flunixim megluminej), sendo que para ambos os fármacos, as doses foram calculadas por extrapolação alométrica interespecífica. O pósoperatório consistiu em limpeza diária da ferida cirúrgica, utilizando gluconato de clorexidina $4 \%$, por um período de cinco a sete dias. A evolução clínica de cada animal foi anotada em fichas individuais após o implante.

Todos os grupos passaram por avaliação radiológica imediata e em períodos quinzenais após a cirurgia. Após eutanásia, o úmero foi coletado para avaliação, aos 15 dias (grupo 15), 30 (grupo 30), aos 60 (grupo 60), e aos 90 dias de pós-operatório (grupo 90). Para a prática da eutanásia, os animais foram submetidos à anestesia geral com o uso de cloridrato de cetamina e posteriormente colocados em um recipiente fechado contendo algodão encharcado com 
éter sulfúricol. Depois de desarticulado, tanto distal quanto proximal, o úmero de cada ave foi separado de sua pele e musculatura adjacente, cortado transversal e longitudinalmente, para a avaliação macroscópica. Em seguida, foi fixado em formol tamponado a $10 \%$ e enviado para avaliação histopatológica. Para isso, foi procedida a descalcificação, fixação em parafina, coloração com a técnica de hematoxilina-eosina (H.E.) e análise em microscópio óptico.

\section{RESULTADOS E DISCUSSÃO}

O protocolo anestésico utilizado, com doses calculadas por extrapolação alométrica interespecífica, foi eficiente para a realização dos procedimentos cirúrgicos, não sendo necessária complementação de dose bem como foram raras as vezes em que se usou a anestesia inalatória durante a cirurgia. Os fármacos utilizados e a forma de calcular as doses são, segundo BOLSON (2004), freqüentemente utilizados por pesquisadores em animais com metabolismo acelerado e um exemplo pode ser citado com a pesquisa de PACHALY et al. (2001) que assim procederam para anestesiar patos (Cairina moschata) submetidos à cirurgia de contenção de vôo com resultados satisfatórios.

O procedimento cirúrgico de implantação do pino de poliuretana foi realizado sem dificuldades, devido, além do bom plano anestésico, à facilidade de acesso à articulação escápula-coraco-umeral e a técnica de introdução normógrada, através do tubérculo umeral. A técnica de introdução normógrada através do tubérculo umeral foi escolhida, pois além de causar menores danos aos tecidos moles, inclusive nervo radial, possibilita o retorno funcional do membro rapidamente sem precisar de estabilização após implantação do material. Segundo JACKSON (1996) e PIERMATTEI \& FLO (1999), o método normógrado de inserção de pinos intramedulares no úmero pode ser útil para a redução de fraturas proximais, diafisárias e distais sem maiores lesões aos tecidos circunjacentes.

Durante a avaliação clínica pósoperatória, notou-se retorno funcional do membro, em posição anatômica, imediatamente após recuperação anestésica e a cicatrização da ferida cirúrgica, em geral, entre dois e quatro dias, sem sinais de infecção. Conforme FOWLER (1978), a rápida cicatrização em aves deve-se ao fato de o seu metabolismo ser acelerado em relação ao dos mamíferos e a ausência de infecção é fator determinante. Também não foram observadas alterações na temperatura local e geral, no comportamento, apetite e função mecânica do membro operado. Com base na avaliação clínica, afirma-se não existir qualquer rejeição ao implante da poliuretana nos animais testados. Condições clínicas semelhantes também foram observadas em cães por IGNÁCIO (1999) e MARIA et al. (2004), em coelhos por OHARA et al. (1985) e SILVA (2000) e em camundongos por VILARINHO et al. (1996).

As radiografias (Figura 1) revelaram aumento de densidade no seio do osso em todos os períodos de avaliação. Resultados semelhantes foram obtidos por DEL CARLO et al. (2003), que observaram aumento de radiopacidade no local de implantação da poliuretana em coelhos. Não houve alterações patológicas no seio do osso, região da cabeça umeral, tecidos adjacentes e nos sacos aéreos das aves estudadas. Observações semelhantes foram notadas em cães por MARIA et al. (2004). Através do estudo radiográfico, foi possível notar características de biocompatibilidade como a integridade óssea, não reação periosteal e articular, ausência de proliferação óssea, cistos, seqüestro ou irregularidades no osso submetido à implantação da poliuretana de mamona em codornas. Segundo SILVA (1997), imagens radiográficas convencionais são eficientes na avaliação do comportamento biológico de um biomaterial.

$\mathrm{Na}$ análise macroscópica em corte longitudinal e transversal, observou-se que a poliuretana não foi absorvida em nenhum dos quatro grupos, permanecendo implantada no seio do osso pneumático (Figura 2). Notaram-se alterações na consistência do pino pré-moldado, que se tornou menos resistente com o passar do tempo. Esses resultados corroboraram com os de MARIA et al. (2003), porém esses autores não relataram alterações na resistência da poliuretana. Segundo CLARO NETO (1997), a poliuretana trata-se de um material bastante resistente à tração e compressão. Esses resultados foram obtidos através de uma pesquisa sobre caracterizações físico-químicas da poliuretana de mamona.

Não se obteve informações sobre a resistência do material após a implantação, mas essa característica pode ser resultado da absorção do cálcio utilizado na preparação do material, bem como pela hidratação e “amolecimento”, por líquidos corporais, do material implantado. Macroscopicamente não se detectou nenhum tipo de reação que propusesse intolerância ao material.

Histologicamente, a resina, quando não permeada por tecido ósseo, apresentou-se como

Ciência Rural, v. 35, n. 5, set-out, 2005. 


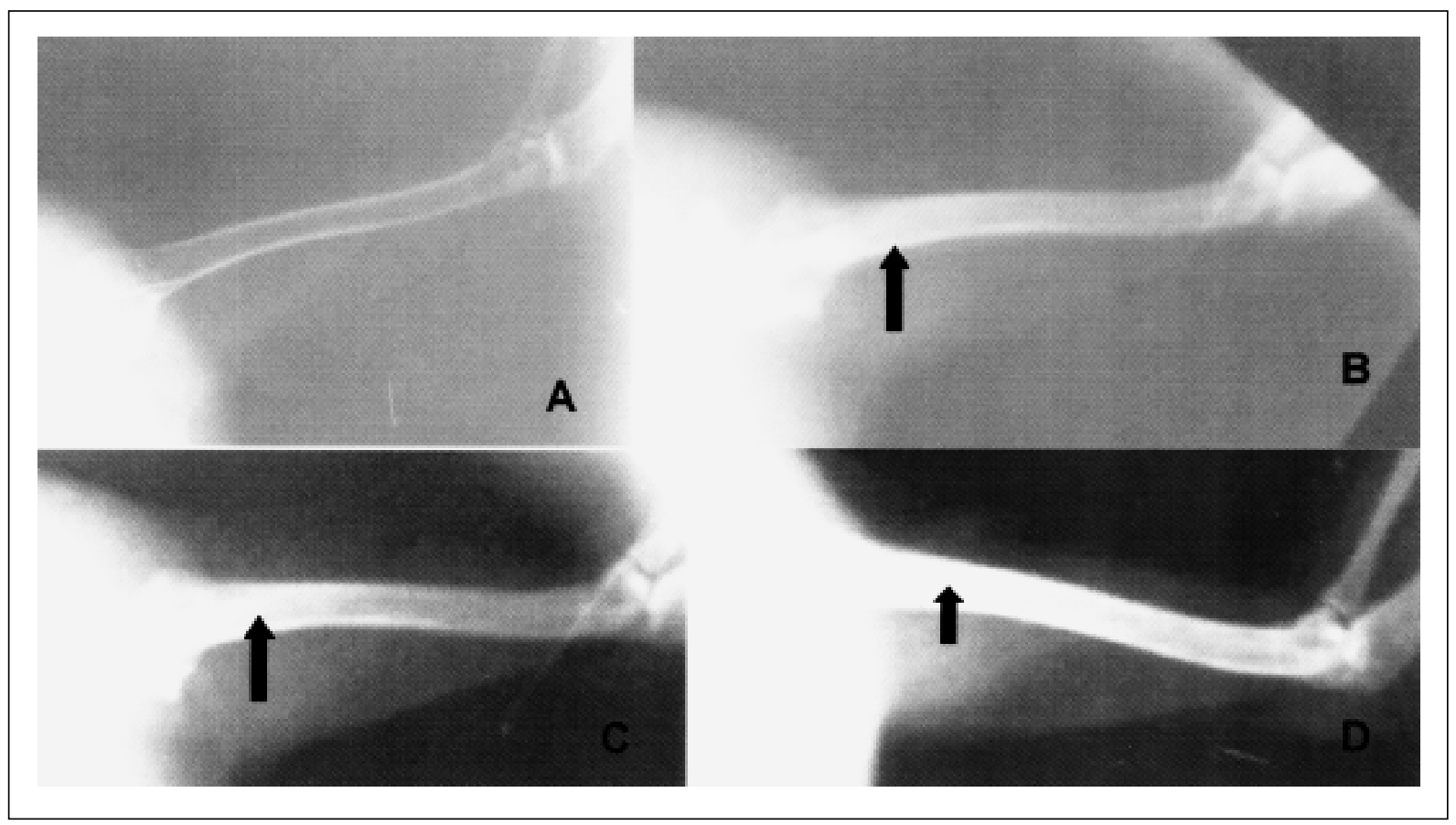

Figura 1 - Imagens fotográficas, da avaliação radiológica utilizando-se Kv de 45 e mA autorregulável, em posição médio-lateral, pós-operatória, do úmero de codornas domésticas (Coturnix japonica), submetidas ao implante da poliuretana derivada da mamona (Ricinnus communis). Imagem de um osso normal (A), de avaliações aos tempos 15 (B), 60 (C) e 90 (D) dias de pós-operatório. Notar a ausência de reação óssea e periosteal e o aumento da radiopacidade (setas), no seio dos ossos implantados, em relação ao osso normal.

material amorfo e translúcido, de coloração amarelada clara que, quando examinada sob luz polarizada, exibia birrefringência irregular multifocal, com múltiplos vacúolos irregulares opticamente vazios (Figura 3A). A resina demonstrou excelente compatibilidade com o tecido ósseo. As alterações histopatológicas causadas pela presença da resina no seio do osso foram mínimas e caracterizam-se apenas por reação inflamatória leve, em período inicial de avaliação. Esta, quando presente, consistiu de infiltração leve de heterófilos e deposição discreta de fibrina (Figura 3B). A resina adaptou-se totalmente aos contornos do osso do canal medular e demonstrou excelente integração com o tecido ósseo. A osteointegração foi constatada em todas as amostras examinadas e foi evidenciada pela presença de trabéculas ósseas, e freqüentemente medula óssea, preenchendo os espaços vazios da resina (Figura 3C e 3D). CALIXTO et al. (2001) implantaram a poliuretana na cavidade alveolar de ratos e o material mostrou-se biocompatível, sem sinais de resposta inflamatória persistente, capaz de certo grau de osteointegração observado por acúmulo progressivamente maior de tecido ósseo em maturação, que em algumas regiões estabelecia contato direto com o implante. Contudo a osteointegração não foi observada em cães por MARIA et al. (2003). Essas ocorrências enriquecem a hipótese desse autor de que a poliuretana de mamona comporta-se de forma diferente entre as espécies.

\section{CONCLUSÃO}

A análise dos dados clínicos, radiológicos, macroscópicos e histológicos possibilita a afirmação de características biocompatíveis, e a análise histológica a característica de osseointegração da poliuretana derivada do óleo da mamona (Ricinus communis) implantada em ossos de codornas domésticas (Coturnix japonica), caracterizando-se um material opcional para utilização em cirurgia ortopédica aviária.

Os estudos com o polímero de mamona devem ser continuados, pois pouco se sabe ainda sobre características como a resistência mecânica do material após sua implantação.

Ciência Rural, v.35 n. 5, set-out, 2005. 


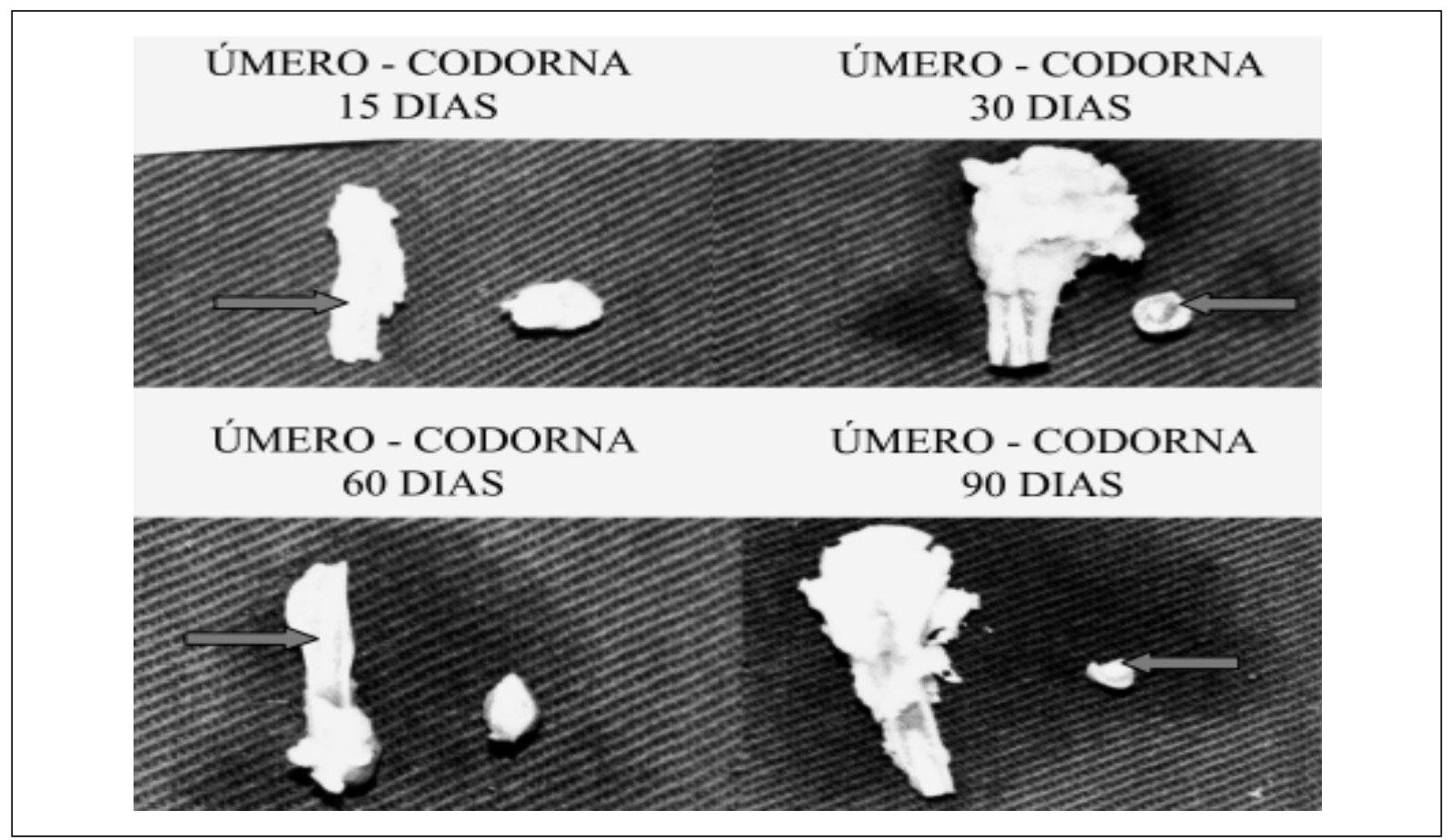

Figura 2 - Imagens fotográficas mostrando a seqüência da avaliação macroscópica, do úmero de codornas domésticas (Coturnix japonica), submetidas ao implante da poliuretana de mamona (Ricinnus communis). Notar a presença da poliuretana, dentro do seio medular, nos cortes longitudinais e transversais (setas), nos vários períodos de avaliação.

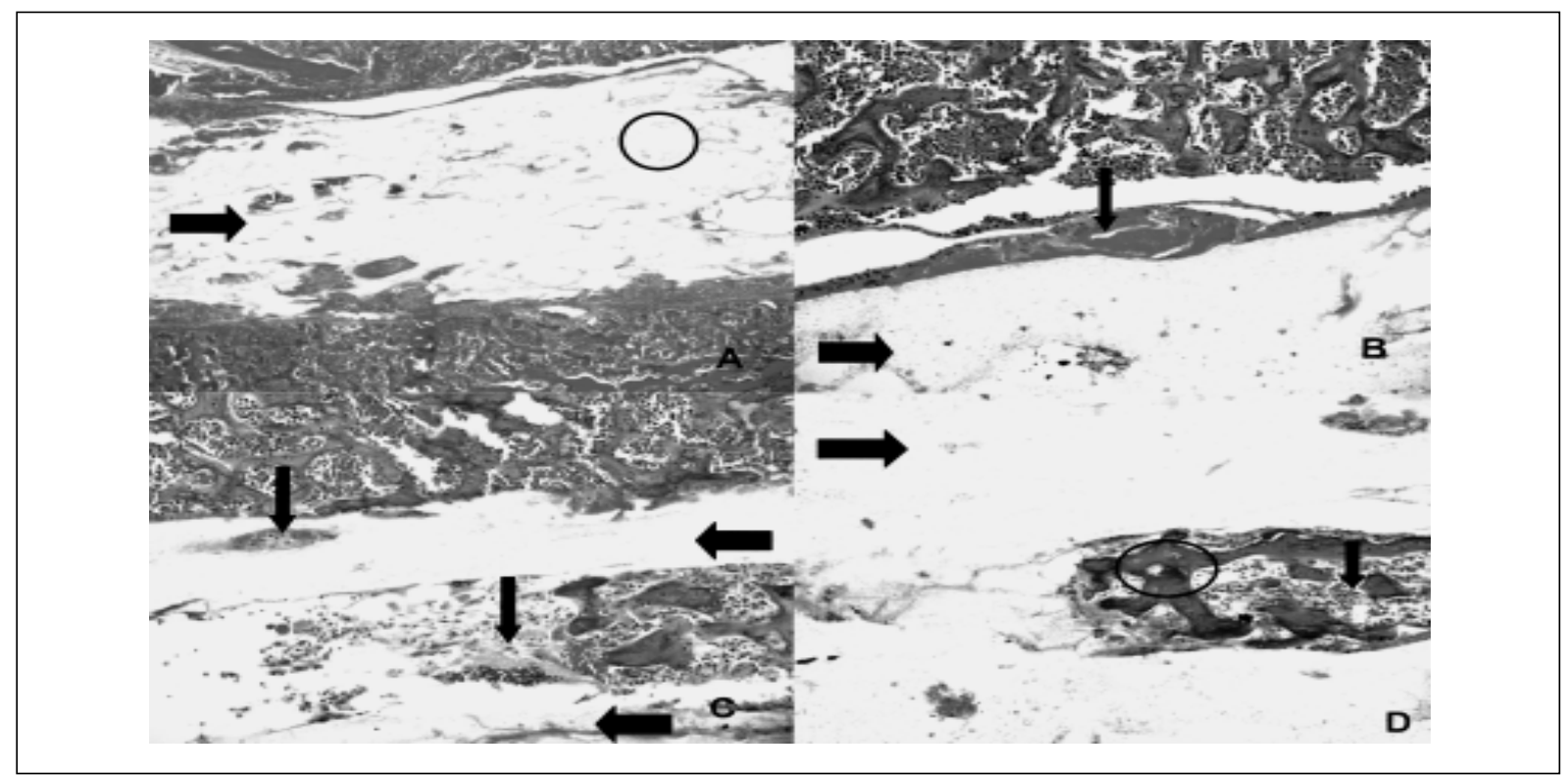

Figura 3 - Imagens fotográficas da avaliação histológica do úmero de codornas domésticas (Coturnix japonica), submetidas ao implante da poliuretana derivada da mamona (Ricinnus communis). A, (objetiva $5 \mathrm{x}$ ), representa um corte longitudinal de úmero de codorna do grupo 30 exibindo a poliuretana no interior do seio medular (seta). Notar os vacúolos opticamente vazios (círculo). B (objetiva 10x) representa um corte longitudinal do úmero de codorna do grupo 15 exibindo a poliuretana (seta grossa), no interior do seio medular. Notar a presença de discreta deposição de fibrina com infiltração de heterófilos na periferia da poliuretana (seta fina). C (objetiva 10x) e D (objetiva 20x) representam um corte longitudinal do úmero de codorna do grupo 60 exibindo a poliuretana no interior do seio medular (seta grossa). Notar a osteointegração em C (seta fina), caracterizada por presença de trabéculas ósseas (círculo) e medula óssea (seta fina) em D.

Ciência Rural, v. 35, n. 5, set-out, 2005. 


\section{AGRADECIMENTOS}

Ao CNPq pelo auxílio financeiro e à Biomecânica pelo fornecimento do Bioosteo ${ }^{\circledR}$.

\section{FONTES DE AQUISIÇÃO}

${ }^{\mathrm{a}}$ Ketamin-S(+) - Cristália, ${ }^{\mathrm{b}}$ Rompun ${ }^{\circledR}$ - Bayer, ${ }^{\mathrm{c} A t r o p i n a-~}$ Hypofarma, ${ }^{\mathrm{d}}$ Fentanest - Cristália, ${ }^{\mathrm{e} H a l o t h a n o ~-~ C r i s t a ́ l i a, ~}$ ${ }^{\mathrm{f}}$ Gluconaco de clorexidina - Manipulação, ${ }^{\mathrm{g}}$ Bioosteo ${ }^{\circledR}$ Biomecânica, ${ }^{\text {h}}$ Vicryl - Ethicon, ${ }^{i}$ Baytril ${ }^{\circledR}$ - Bayer, ${ }^{\text {B Banamine }}{ }^{\circledR}$ Shering-Plugh Veterinária, 'Éter sulfúrico - Cristália.

\section{REFERÊNCIAS}

ALIEVI, M.M. Redução fechada e fixação esquelética externa tipo I ou tipo II para o tratamento de fratura de tibiotarso em pombos domésticos. 2000. 38 f. Dissertação (Mestrado em Cirurgia Veterinária) - Programa de Pós-graduação em Medicina Veterinária, Universidade Federal de Santa Maria.

BAYER, C. Biomecânica - Polímero osteointegrável Bioosteo. Capturado em 10 abr. 2003. Online. Disponível na internet http://www. biomecânica.com.br/bioosteo/index.htm

BOLSON, J. Procedimentos cirúrgicos em animais selvagens e silvestres. In: I SIMPÓSIO GAÚCHO SOBRE ANIMAIS SELVAGENS, 2004. Santa Maria, RS, Brasil. Anais... Santa Maria: Universidade Federal de Santa Maria - UFSM, 2004. 1 Cd room. Para uso em PC.

BUSH, M. External fixation of avian fractures. Journal of the American Veterinary Medical Association, v.171, n.9, p.943946, 1977.

CALIXTO, R. F. E.et al. Implantation of flakes of castor oil resin in rat dental alveolus. Pesquisa Odontológica Brasileira, v. 15, n. 3, p. 257-262, 2001.

CAVALCA, D. Ageuniara - USP desenvolve osso artificial a partir do óleo de mamona. Capturado em 12 abr. 2003. Online. Disponível na Internet http://www.uniara.com.br/ageuniara/ artigos.asp/Artigo $=27$

CHIERICE, G. Ageuniara - USP desenvolve osso artificial a partir do óleo de mamona. Capturado em 12 abr. 2003. Online. Disponível na Internet http://www.uniara.com.br/ageuniara/ artigos.asp/Artigo $=27$

CLARO NETO, S. Caracterização físico-químicas de um poliuretano derivado de óleo de mamona utilizado para implantes ósseos. 1997. 127f. Tese (Doutorado) - Instituto de Química de São Carlos, Universidade de São Paulo.

DEL CARLO, R.J. et al. Polímero derivado de mamona acrescido de cálcio, associado ou não à medula óssea autógena na reparação de falhas ósseas. Ciência Rural, Santa Maria, v.33, n.6, 2004. P. 1081-1088.

FOWLER, M.E. Zôo and wild animal medicine. Philadelphia: Lea \& Febiger, 1978.

HIRAKI, K. Biocompatibilidade in vitro do polímero de mamona. Capturado em 12 Abr. 2003. Online. Disponível na Internet http://www.usp.br/siicusp/9osiicusp/cd_2001/ ficha153.htm
IGNÁCIO, H., Avaliação da poliuretana da mamona nas formas compacta e porosa no preenchimento de falha óssea. 1999. Tese (Doutorado) Faculdade de Medicina de Ribeirão Preto, Universidade de São Paulo.

JACKSON, D.A., Tratamento das fraturas umerais. In: BOJRAB, M.J. Técnicas atuais em cirurgia de pequenos animais. São Paulo: Roca, 1996. Cap. 47, p.710-724.

MACCOY, D.M. General principles of avian surgery. Compendium on Continuing Education for Practicing Veterinarian, v.13, n.6, p.989-992, 1991.

MACCARTNEY, W.T. Orthopaedic injuries in pigeons Veterinary Record, v.134, n.19, p.305-307, 1994.

MARIA, P.P. et al. Análise macroscópica e histológica do emprego da poliuretana derivada do óleo de mamona (Ricinnus communis) aplicada na tíbia de cães em fase de crescimento. Acta Cirúrgica Brasileira, São Paulo, v.18, n.4, 332-336, 2003.

MARIA, P.P., et.al. Poliuretana da mamona (Ricinnus communis) para desvio da crista da tíbia no cão. Ciência Rural, Santa Maria, v.34, n.3, 2004. p. 821-827.

NEWTON, C.D; ZEITLIN, S. Aviam fracture healing. Journal of the American Veterinary Medical Association, v.170, n.6, p.620-625, 1977.

OHARA, G.H. et al. Estudo experimental da biocompatibilidade do polímero da mamona implantada intra-óssea e intra-articular em coelhos. Acta Ortopedia Brasileira, São Paulo, v.3, n.2, p. 62-68, 1985

PACHALY, J.R. et al. Field trial on chemically restraining muscovy ducks (Cairina moschata) with allometrically scaled doses of xilazine, ketamine and atropine, Umuarama, PR, 2001. In: JORNADA DE MEDICINA VETERINÁRIA DA UNIPAR, VI, 2001, Umuarama, PR. Anais... Umuarama: Arquivos de Ciências Veterinária da Unipar, 2001, v.4, n.2, p.238-246.

PIERMATTEI, D.L.; FLO, G.L. Manual de ortopedia e tratamento das fraturas dos pequenos animais. São Paulo: Manole, 1999. 694p.

PIRES, R., Avaliação da osseocondutividade e osseointegração de implantes com três formulações de poliuretano derivado de mamona em fêmur de coelhos. Capturado em 12 Abr. 2003. Online. Disponível na Internet http://www.usp.br/siicusp/ 9osiicusp/cd_2001/ficha128.htm

SILVA, M.C. Poliuretano de óleo de mamona como substitutivo de tendão: estudo experimental em coelhos (Oryctolagus cunicullus). 2000. 62f. Dissertação (Mestrado em cirurgia) - Escola de Veterinária, Universidade Federal de Minas Gerais.

SILVA, M.J.A. Estudo do comportamento do tecido ósseo frente ao implante do polímero de mamona em rádios de coelhos, pela análise quantitativa das radiopacidades nas imagens radiográficas convencionais. Revista da Faculdade de Odontologia de Bauru, Bauru, v.5, n.3-4, p.69-67, 1997.

TAVANO, O. Estudo da densidade radiográfica digital do tecido ósseo face ao implante do polímero de mamona em coelhos. Revista da Faculdade de Odontologia de Bauru, v.7, n.3-4, p.53-58, jul/dez. 1999.

Ciência Rural, v.35 n. 5, set-out, 2005. 
VILARINHO, R.H. et al. Implante de resina de poliuretana vegetal na câmara anterior de olho de camundongo - estudo histológico, Araraquara, SP, 1996. In: ODONTOLOGIA DO SÉCULO XXI, 1996, Araraquara, SP. Anais... Araraquara: Faculdade de Odontologia, 1996. v.1. p.25-29.

WESTFALL, M.L; EGGER, L.E. The management of long bone fractures in birds. Iowa State Veterinarian, v.41, n.2, p.81-87, 1979.
WILLIAMS, R. et al. A comparative study of treatment methods for long bone fractures. Companion Animal Practice, v.1, n.4, p.48-55, 1987.

WISSMAN, M.A. New tools, diagnostics aid in bone and beak repair in birds. Veterinary Product News, v.11, n.6, p.44-45, 1999.

WITHROW, S.J. General principles of fracture repair in raptors. Compendium on Continuing Education for Practicing Veterinarian, v.4, n.2, p.116-121, 1982. 